\title{
Assessment of Two Engineering Courses in Architectural Engineering Program in UAE University Based on the Comparison of the Students Results with the Students and the Instructors Opinions
}

\author{
Maatouk Khoukhi ${ }^{1, *}$ \\ ${ }^{1}$ College of Engineering, United Arab Emirates University, 15551, Al Ain, UAE \\ *College of Engineering, United Arab Emirates University, 15551, Al Ain, UAE. E-mail: mkhoukhi@uaeu.ac.ae
}

Received: June 29, 2021

Accepted: July 11, $2021 \quad$ Online Published: August 10, 2021

doi:10.5430/wje.v11n4p1

URL: https://doi.org/10.5430/wje.v11n4p1

\begin{abstract}
The present study examined the level of outcome satisfaction of two main engineering courses taken by students in the Architectural Engineering department (AE) by evaluating the students' satisfaction result (SR), the attained level of the students' opinions (SO), and the instructors' opinions (IO). The AE program in United Arab Emirates University is one of the departments in the College of Engineering accredited by the Engineering Accreditation Commission of ABET which provides assurance that a College or University program meets the quality standards of the profession for which that program prepares graduates. The AE program offers a wide range of engineering courses at different levels from sophomore level to senior level. All the engineering courses are mainly prerequisites to the Capstone Engineering Design Project which builds on the outcomes of all courses to perform detailed design and cost estimates of the selected alternative solutions to a well-defined engineering problem. The two courses considered in this study are Building Electrical Circuits and Building Acoustics and Lighting. New assessment parameters which are the student course outcome satisfaction coefficient (SCOSC) and the mean absolute deviation around a central point (AMD) have been introduced in this paper. These two parameters are calculated based on the comparison of the students' satisfaction results with both students' opinions and insructors' opinions, and compare the mean absolute deviations of the students' direct results with the students' opinions and the instructors' opinions, respectively. Indeed, the course learning outcomes (CLOs) of the SR of some sections for both courses show higher attainment compared with the SO and IO.
\end{abstract}

Keywords: building electrical circuit, building acoustics and lighting, Architectural Engineering Program, course assessment, course outcome satisfaction coefficient

\section{Introduction}

Assessment is an important part of instruction and inevitable component, as it determines whether or not the target of education are being met. Assessment affects decisions about grades, placement, advancement, instructional needs, and curriculum. Assessment inspire us to ask these questions: "Are we teaching what we think we are teaching?" "Are students learning what they are supposed to be learning?" "Is there a way to teach the subject better, thereby promoting better learning?" (Wiggins, 2008). Assessment and its associated feedback are essential to student learning (Race, Brown and Smith, 2005). A student undertaking any form of study will be subject to assessment in one form or another. Similarly, any member of teaching staff will be engage at some point in assessment related (Cowan, 2005).

The assessment process in educational system is important and inevitable because it provides feedback and changes are implemented to improve learning (Khonbi and Sadeghi, 2012). Different college programs are assessing and monitoring students learning outcomes by implementing several assessment tools across multiple levels within their institutions (Banta, 2004). Two major methods of courses assessment are being used by academic institutions which are direct and indirect methods. Direct methods of courses assessment demonstrate mastery through exams and assignments for instance. Indirect measures, reflect opinions and are obtained from surveys and interviews (Price and Randall, 2008). 
The architectural engineering (AE) program in the United Arab Emirates University (UAEU) is one of department in the College of Engineering accredited by the Engineering Accreditation Commission of ABET which provides assurance that a College or University program meets the quality standards of the profession for which that program prepares graduates. The AE program offers a wide range of engineering courses at different levels from sophomore to senior levels. All the engineering courses are mainly prerequisite to the capstone engineering design project which builds on the outcomes of all courses to perform detailed design and cost estimate of the selected alternative solutions to a well-defined engineering problem. The two courses considered in this study are the building electrical circuits (BEC) and building acoustics and lighting (BAL) with two different sections for each course. The assessment has been done for the two courses during three different semesters for BEC course and two semesters for the BAL course.

This study will focus on the direct measures of learning outcomes which demonstrate a master of knowledge, and the students and instructor opinions about one's ability. There are several methods of direct measurement as described by (Luce and Kirman, 2016) which include tests, papers, projects and presentations. This direct method administered through the whole semester will identify the increased knowledge gained by the students from the start to the end of the semester (Pederson and White, 2016). To achieve an appropriate paradigm of assessment tools should involve instructors in their creation. Several researchers highlighted the importance to clarify what we want students to learn from the assignments and the build and design the assignments that will help them achieve those goals (Banta, 2015 and Suskie, 2009). New assessment parameters which are the student course outcome satisfaction coefficient (SCOSC) and the mean absolute deviation around a central point (AMD) have been introduced in this paper.

\section{Method}

The target population for this study consisted of undergraduate students in the College of Engineering at the UAEU. Two courses have been considered in this study which are core courses taught in the AE department as mentioned previously. The course learning outcomes (CLOs) for both course are shown in Table 1. Several parameters have been developed in this study and used as comparative tools to assess the attainment levels of the direct results compared with the indirect ones. Indeed, the first index defined is the course outcome satisfaction coefficient (COSC) which represent the comparison of the attainment level of the CLOs of the student results compared with the students' opinions ones. The COSC shows a straightforward comparison between direct and indirect CLOs attainment for each section in each course. The second comparison of the SR is also done with the instructors' opinion. Indeed, this coefficient allows the instructor to get a feedback for each CLOs in each course for each section to provide any corrective action for improvement. The index is related to the ratio between the number of CLOs of students' outcomes attainment higher or equal to the number of CLOs of students' opinions or expectation over the number of the CLOs for the course section. This index is the student course outcome satisfaction coefficient (SCOSC). Finally, a third coefficient which is the mean absolute deviation around a central point (AMD) had been also defined and used in this study to compare the average of the SR with the average of the SO for each course section.

Table 1. Course Learning Outcomes for Each Course

\begin{tabular}{|c|c|c|}
\hline Courses & CLOs \# & CLOs Statment \\
\hline \multirow[t]{5}{*}{$\mathrm{ARCH} 341$} & 1 & $\begin{array}{l}\text { Knowledge of electric components and basic circuits (DC \& AC), building circuits } \\
\text { (single-phase \& three-phase) }\end{array}$ \\
\hline & 2 & The ability to analyze electric circuits to specify and/or find voltage, current, and power \\
\hline & 3 & The ability to estimate lighting and power loads (appliances and equipment). \\
\hline & 4 & $\begin{array}{l}\text { The ability to design electrical system: lighting and power loads, safety and protection, \& } \\
\text { distribution systems }\end{array}$ \\
\hline & 5 & $\begin{array}{l}\text { The ability to use electrical wiring regulations in the design - as well as basic inspection } \\
\text { and testing - of building electrical systems }\end{array}$ \\
\hline \multirow[t]{5}{*}{$\mathrm{ARCH} 342$} & 1 & Introduce the students to the basics of lighting design \\
\hline & 2 & Familiarize the students with the different light sources and fixtures \\
\hline & 3 & $\begin{array}{l}\text { Help the students to understand lighting design principles to be able to communicate with } \\
\text { lighting designers }\end{array}$ \\
\hline & 4 & Familiarize the students with Sound and Noise control in buildings \\
\hline & 5 & Help the students to be able to communicate with acoustical consultants \\
\hline
\end{tabular}


The equation of the three defined coefficients are shown as follow:

1. Course Outcome Satisfaction Coefficient (COSC): represents the number of the CLOs of SR $>=<\mathrm{SO}$ which is given by the following equation

$$
\text { OSC }=\text { Nbre of CLOs of SR }>=<\text { SO }
$$

2. Student Course Outcome Satisfaction Coefficient (SCOSC): represents the Ratio between the number of CLOs attainment for SR higher or equal to the SO over the number of the CLOs given by

$$
S C O S C=\frac{\text { Nbre of CLOS of SR } \geq N \text { bre of CLOS of SO }}{\text { Nbre of CLOS }}
$$

3. The Mean Absolute Deviation around a central point (AMD) is the comparison between the average of the SR with the average of the $\mathrm{SO}$ and $\mathrm{IO}$ for each course section and given as below:

$$
A M D=\frac{1}{n} \sum_{1}^{n}\left|x_{i}-m_{(x)}\right|
$$

Where $\mathrm{n}$ is the number of CLOs, $x_{i}$ is the average of the SR, and $m_{(x)}$ is the central tendency which represents the average of the $\mathrm{SO}$ and IO.

\section{Results and Discussion}

All the details and comparison between the SR with the SO and IO for both courses for all sections are shown below in Figs. 1-10. Fig. 1 is related to the result of the SR, SO, and IO for ARCH341 during fall 2015 for section 51. Indeed, SR for CLO1 and CLO2 are below the SO results. These two CLOs are related to the basic knowledge gained by the students in physics which may indicate lack of knowledge gained by the students in the previous prerequisite courses. Meanwhile, the CLO4 and CLO5 which are linked with the design part of the course are above the SO. For the section 52, still the SR of CLO2 is below the SO and the SR of CLO1 is equal to the SO. Regarding fall 2016, the SR values are all below the SO for all the CLOs which could be attributed to the lack of basic sciences gained in the prerequisite courses for section 51. However, the SR of CLO3, CLO4, and CLO5 are above the SO for the section 2 with an average of SR for all CLOs equal to the average for the SO. In the fall 2017, the SR are higher than the SO for all CLOs in section 51. But the opposite result is obtained for the section 52. Indeed only the SR of CLO5 is equal to the SO and the SR for the remaining CLOs are below the SO.

The student course outcome satisfaction coefficient (SCOSC) summarizes the percentage of the student course attainment which indicates the number of SR higher or equal to the SO for all CLOs as shown by table 2.

Table 2. The Student Course Outcome Satisfaction Coefficient for Both Courses

\begin{tabular}{lccccc}
\hline & \multicolumn{3}{c}{ ARCH 341 } & \multicolumn{2}{c}{ ARCH 342 } \\
& Fall 2015 & Fall 2016 & Fall 2017 & Spring 2016 & Spring 2018 \\
\hline Section 1 & $60 \%$ & $0 \%$ & $100 \%$ & $60 \%$ & $80 \%$ \\
Section 2 & $80 \%$ & $60 \%$ & $20 \%$ & $20 \%$ & $40 \%$ \\
\hline
\end{tabular}

Indeed, different percentages are registered in Table 2 for both courses at different semesters. For instance, in fall 2016 the SCOSC registered 0\% attainment for ARCH341 which means that all the student's results are below the student's opinions for all the CLOs. However, in the following academic year, fall 2017, all the SR of the registered students in the course are higher than the expectations. 


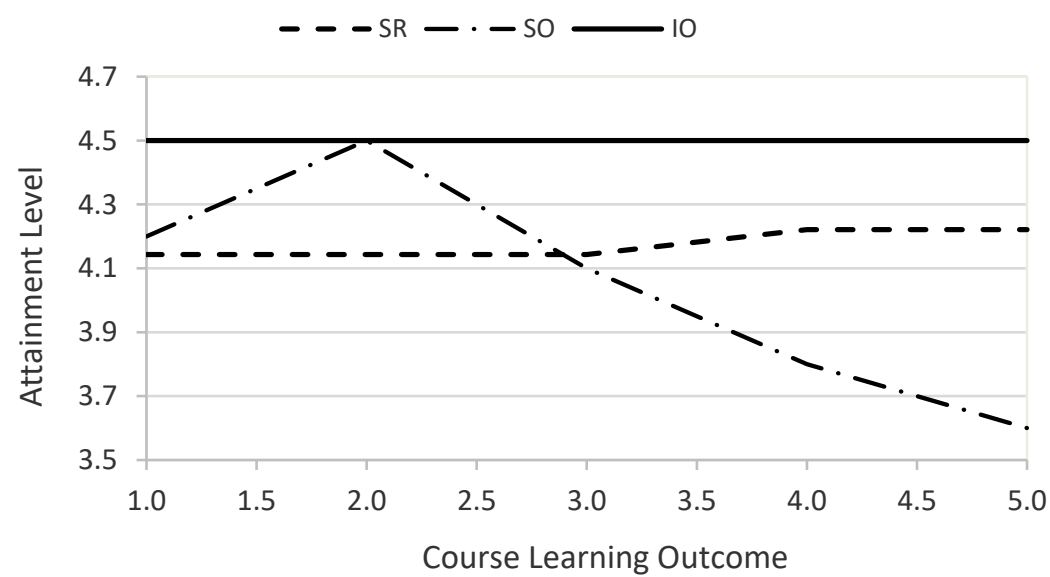

Figure 1. ARCH341 Fall 2015 Section51

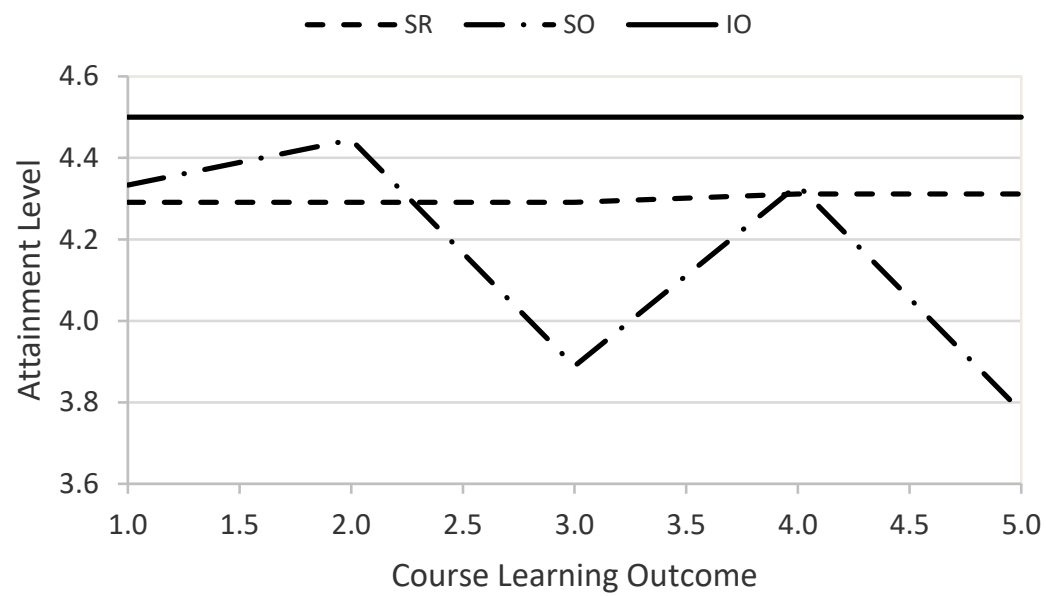

Figure 2. ARCH341 Fall 2015 Section52

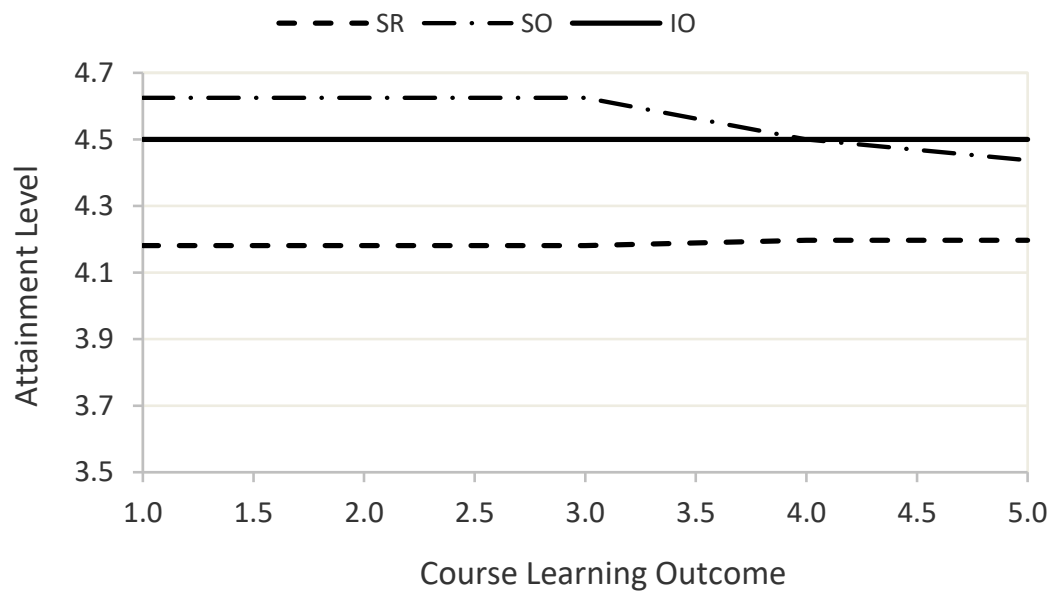

Figure 3. ARCH341 fall 2016 Section51 


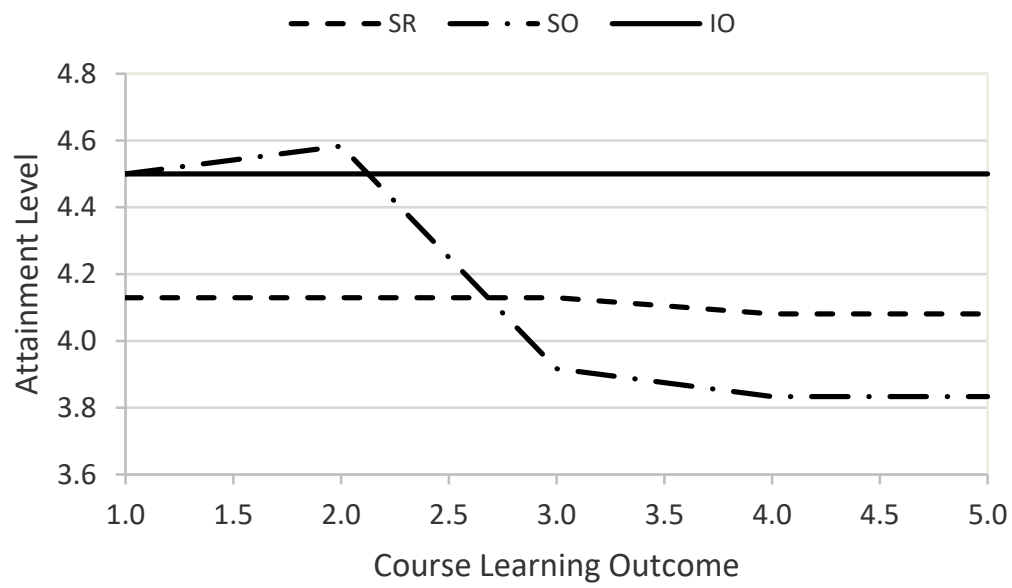

Figure 4. ARCH341 Fall 2016 Section 52

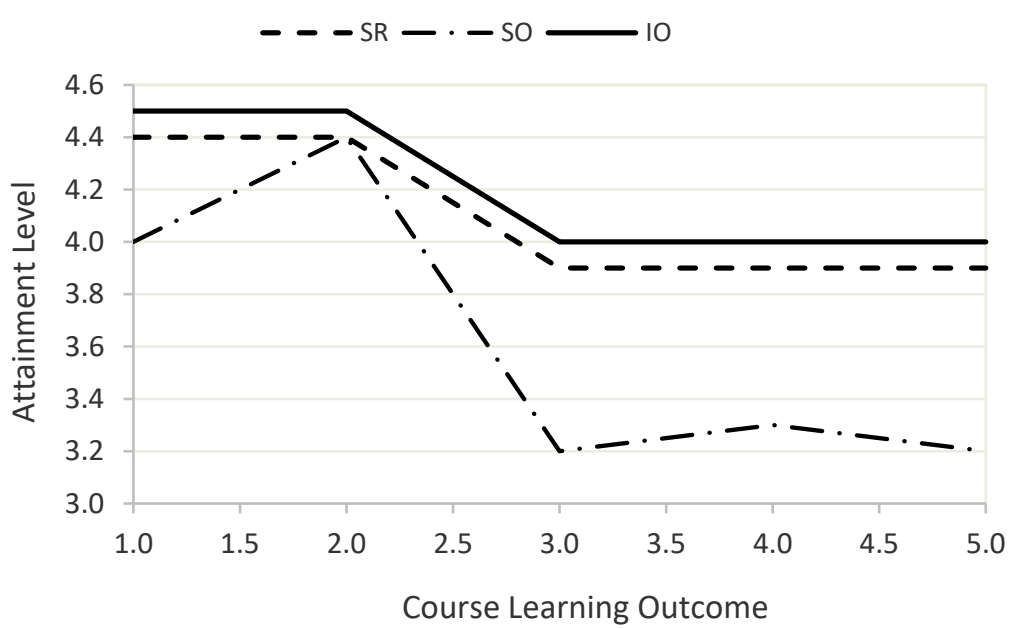

Figure 5. ARCH341 Fall 2017 Section 51

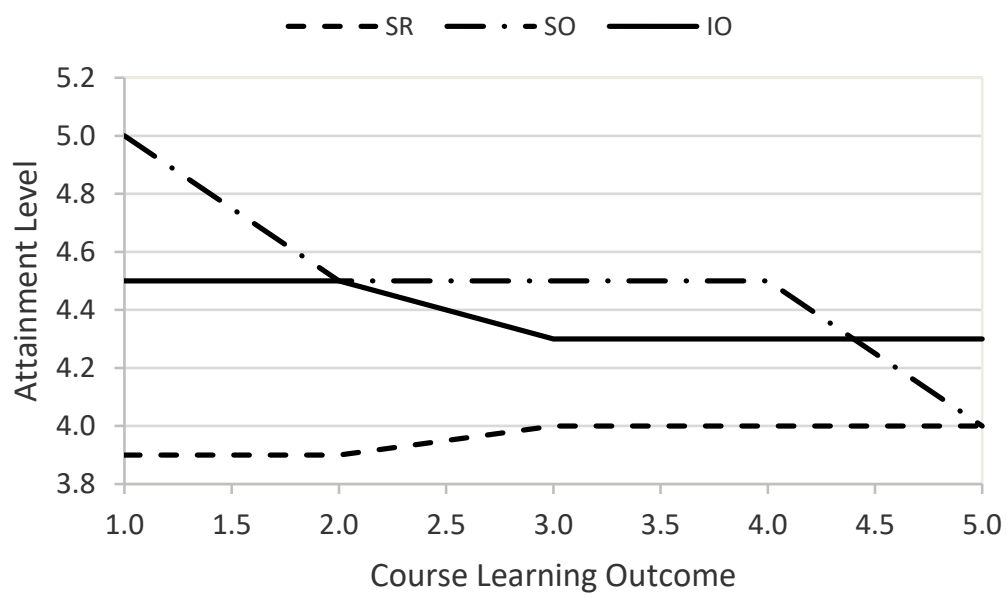

Figure 6. ARCH341 Fall 2017 Section 52 
Fig. 7 shows that the SR of CLO1 and CLO2 are below the SO for the ARCH342 during the spring 2016. We should mention here that the ARCH341 is a prerequisite to ARCH342. However, at that time the ARCH 341 was allowed to be taken as a co-requisite to 342 which could have negative impact on the SR obtained in the two first CLOs which are related to the illumination part, whereas CLO4 and CLO5 are related to the noise and acoustics part of the course. The same tendency is observed for section 52 as shown in Fig. 8. Indeed, only the SR of CLO5 is higher to the SO and the SR of the remaining CLOs are quite far behind the SO. The SR results for the spring 2018 are shown in Fig. 9 where only the SR of CLO1 is lower than the SO. On the other side, the SR of CLO5 is the only one that registered higher value than the SO.

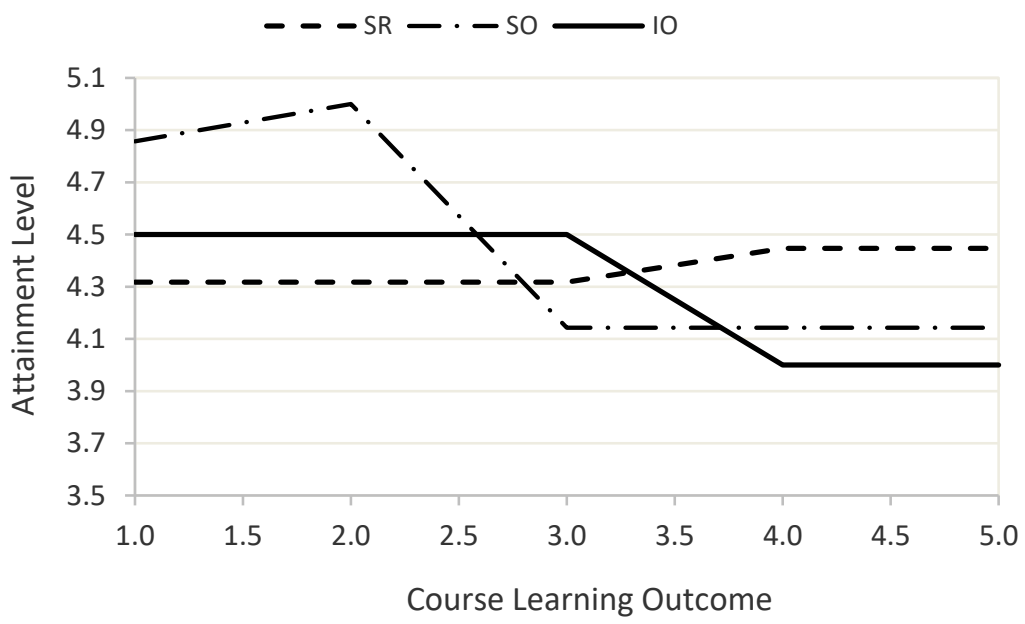

Figure 7. ARCH342 Spring 2016 Section 51

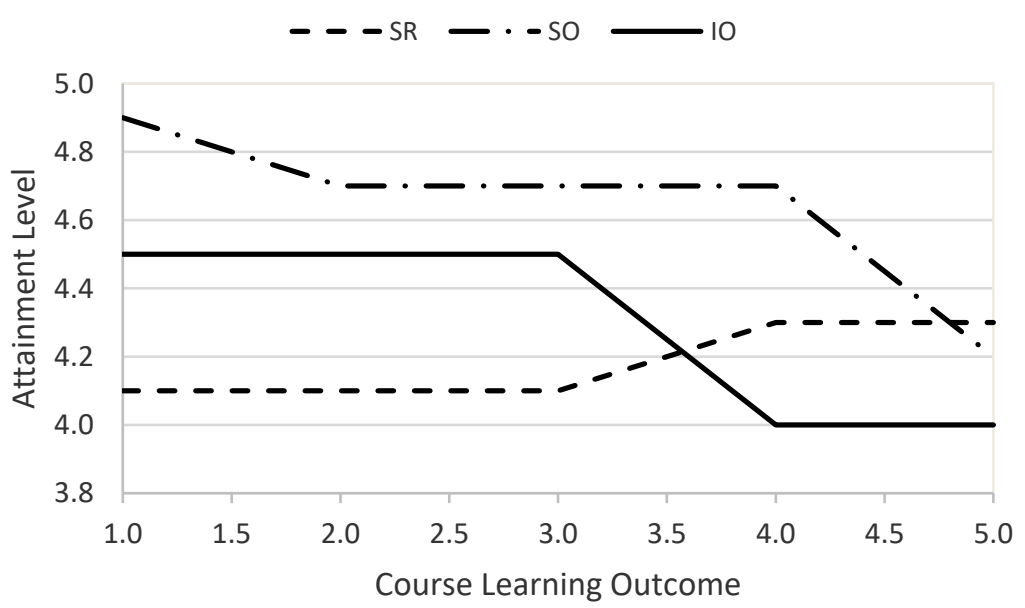

Figure 8. ARCH342 Spring 2016 Section 52

The Mean Absolute Deviation around a central point (AMD) as given by Eq. 3 is shown by Table 3 which summarizes and compare the mean absolute deviations of the students' direct results with the students' opinions and the instructors' opinions. Lower is the AMD smaller is the deviation from the direct and the indirect assessment which indicates better expectation from the students and the instructor towards the direct results obtained by the students through exams and class assignments. There is another parameter that should be also considered in this study which is the number of students in each section. Indeed, this is a critical parameter that should be taken into account and included in the developed approach. 


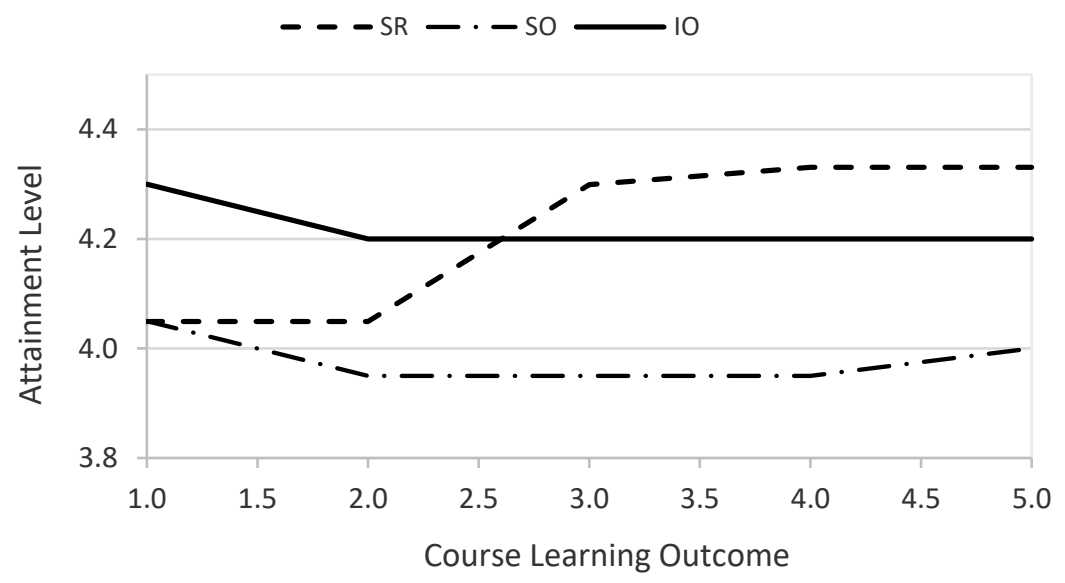

Figure 9. ARCH342 Spring 2018 Section 51

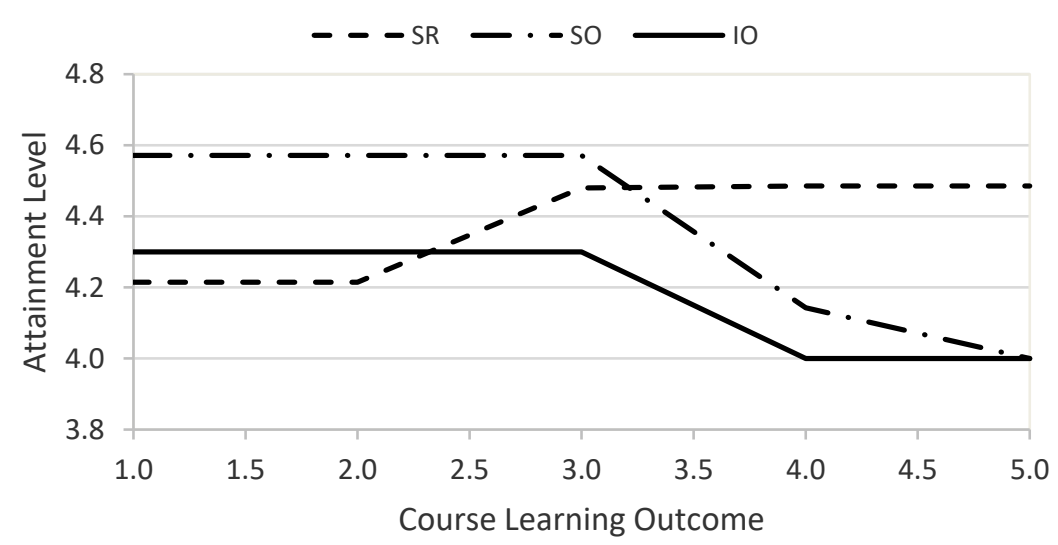

Figure 10. ARCH342 Spring 2018 Section 52

Table 3. The Mean Absolute Deviation of the SR Around the SO and the IO

\begin{tabular}{ccccccc}
\hline & \multicolumn{3}{c}{ ARCH 341 } & \multicolumn{2}{c}{ ARCH 342 } & \\
\hline \multirow{2}{*}{ Section 1 } & SO & 0.2 & 0.4 & 0.5 & 0.1 & 0.2 \\
& IO & 0.3 & 0.3 & 0.3 & 0.1 & 0.1 \\
Section 2 2 & SO & 0.1 & 0 & 0.5 & 0.4 & 0.1 \\
& IO & 0.2 & 0.4 & 0.4 & 0.1 & 0.2 \\
\hline
\end{tabular}

\section{Conclusion}

The present study examined the level of outcome satisfaction of two main engineering courses taken by students in the Architectural Engineering department at The UAE University by evaluating the students' satisfaction result (SR), the attained level of the students' opinions (SO), and the instructors' opinions (IO). A new assessment parameter which is the student course outcome satisfaction coefficient (SCOSC) has been introduced in this paper and calculated based on the comparison of the SR with both SO and IO.

The student course outcome satisfaction coefficient (SCOSC) summarizes the percentage of the student course attainment which indicates the number of SR higher or equal to the SO for all CLOs, and the Mean Absolute Deviation around a central point (AMD) summarizes and compare the mean absolute deviations of the students' direct results with the students' opinions and the instructors' opinions. 
We should mentione that the ARCH341 is a prerequisite to the AECH342 in the revised updated students' study plan. However, during several semesters, the students were allowed to take both courses at the same time which may have negative impact on the students' results. Indeed, more restricted rules have been set recently to ensure that the sequence of courses is well implemented by the students to avoid any backdraw on some courses. Moreover, further courses in the AE program should be also assessed particularly the final design projects and other courses taken by the senior undergraduate students, which have direct impact on the overall students performances during their time spent at the UAE University.

This method will provide instructors feedback on the students' achievements and their expectations with the instructors' opinions. Indeed, this developed method should be extended to all courses taught in any engineering program providing the availability of the students' results along with the students' and instructors' opinions.

\section{References}

Banta, T. W. (2004). Developing assessment methods at classrooms, unit, and university-wide levels. Assessment $\begin{array}{llllll}\text { workshop } & \text { series } & - & \text { No } & 4 . & \text { Retrieved }\end{array}$ https://www.academia.edu/161594/Developing_a_variety_of_assessment_methods

Banta, T. W., \& Palomba, C. A. (2015). Assessment Essentials: Planning, Implementing, and Improving Assessment in higher Education (2nd ed.). San Francisco, CA: Jossey-Bass.

Cowan, J. (2005). Designing assessment to enhance student learning. Retrieved from http://www.heacademy.ac.uk/assets/ps/documents/practice_guides/practice_guides/ps0069_designing_assessme nt_to_improve_physical_sciences_learning_march_2009.pdf

Khonbi, Z. A., \& Sadeghi, K. (2012). The Effect of Assessment Type (self vs. peer vs. teacher) on Iranian University EFL Students' Course Achievement. Language Testing in Asia, 2(4), 47-73. https://doi.org/10.1186/2229-0443-2-4-47

Luce, C., \& Kirman, J. P. (2016). Using Indirect vs. Direct Measures in the Summative Assessment of Student Learning in Higher Education. Journal of the Scholarship of Teaching and Learning, 16(4), 75-91. https://doi.org/10.14434/josotl.v16i4.19371

Pederson, D. E., \& White, F. (2011). Using a Value-added Approach to assess the Sociology Major. Teaching Sociology, 39(2), 138-149. https://doi.org/10.1177/0092055X11400437

Price, B. A., \& Randall, C. H. (2008). Assessing Learning Outcomes in Quantitative Courses: Using Embedded Questions for Direct Assessment. Journal of Education for Business, 83(5), 288-294. https://doi.org/10.3200/JOEB.83.5.288-294

Race, P., Brown, S., \& Smith, B. (2005). 500 Tips on assessment (2nd ed.). London: Routledge. https://doi.org/10.4324/9780203307359

Suskie, L. (2009). Assessing Student Learning: A common Sense Guide (2nd ed.). San Francisco, CA: Jossey-Bass, By John Wiley and Sons.

Wiggins, G. (2008). Retrieved from https://www.edutopia.org/assessment-guide-importance

\section{Copyrights}

Copyright for this article is retained by the author(s), with first publication rights granted to the journal.

This is an open-access article distributed under the terms and conditions of the Creative Commons Attribution license (http://creativecommons.org/licenses/by/4.0/). 